Lu, Y, Broughton, JG and Winfield, PH

A Review of Innovations in Disbonding Techniques for Repair and Recycling of Automotive Vehicles.

Lu, Y, Broughton, JG and Winfield, PH (2014) A Review of Innovations in Disbonding Techniques for Repair and Recycling of Automotive Vehicles.International Journal of Adhesion and Adhesives, 50 (). pp. 119-127.

doi: 10.1016/j.ijadhadh.2014.01.021

This version is available: https://radar.brookes.ac.uk/radar/items/c589d6de-b181-42a2-85be-10557a68a20d/1/

Available on RADAR: February 2016

Copyright (C) and Moral Rights are retained by the author(s) and/ or other copyright owners. A copy can be downloaded for personal non-commercial research or study, without prior permission or charge. This item cannot be reproduced or quoted extensively from without first obtaining permission in writing from the copyright holder(s). The content must not be changed in any way or sold commercially in any format or medium without the formal permission of the copyright holders.

This document is the post print version of the journal article. Some differences between the published version and this version may remain and you are advised to consult the published version if you wish to cite from it. 


\section{A Review of Innovations in Disbonding Techniques for Repair and Recycling of Automotive Vehicles}

Yuchen Lu*, James Broughton, Pat Winfield.

Oxford Brookes University, the United Kingdom.

*Corresponding author. Department of Mechanical Engineering and Mathematical Sciences (MEMS), Oxford Brookes University, Wheatley Campus, Wheatley, OXFORD, OX33 1HX, UK. Email: yuchen.lu-2012@brookes.ac.uk. Telephone: +44 (0)1865 483568.

\section{ABSTRACT}

The recycling, recovery and reuse of End-of-Life Vehicles (ELVs) has raised worldwide concerns. This paper identified drivers for new joining solutions in the automotive industry and specifically reviewed current use of adhesive technology. From an ELV recycling point of view, rapid assembly and disassembly joining solutions were identified as key technology drivers. Innovations in adhesive disbonding technologies were reviewed and suggestions for the most promising future disbonding technologies have been proposed.

KEYWORDS: Disbonding, Adhesive, End-of-Life Vehicles, Automotive, Recycling, Reuse. 


\section{Introduction}

Data issued by the International Organisation of Motor Vehicle Manufacturers showed that the global automotive industry has gradually recovered from the economic crisis in 2008; global vehicle production reached 84.1 million units in 2012 compared to 61.8 million units in 2009 [1]. This can mainly be attributed to the significant increases in vehicle ownership seen in developing countries such as China and India. In 2009 for example, car production in China was the highest of all car producing countries, reaching 13.79 million [2]. From a sustainable development perspective, growing concerns have been raised about the environmental impacts of automotive vehicles and their increasing numbers, including energy consumption, greenhouse gas emissions, waste generation and end-of-life vehicle (ELV) recycling.

The objective of this paper is to investigate the latter of these concerns, particularly focusing on ELV recycling problems from a joining solution perspective. In section two, current ELV processing procedures and legislative initiatives have been reviewed and analysed. Challenges which are likely to be incurred by the production of future vehicles have also been taken into consideration. A new joining solution with the essential characteristic of rapid disassembly is identified as a key technology driver. Section three discusses the current use of adhesive bonding in the automotive industry and a thorough review of recent innovations in adhesive disassembly technology is provided in section four. 


\section{Drivers for Change}

There are two main drivers for change. These are international legislation on ELV and the demand (including future security of supply) of materials.

\subsection{End-of-life Vehicles (ELVs)}

\section{Processing of End-of-Life Vehicles}

End-of-life vehicles are normally either scrapped for recycling or simply abandoned on the road. In terms of the latter choice, the abandoned vehicles not only cause obstruction and safety problems in the public place but also waste resources. The research conducted by Melissa et al. showed that the devaluation of scrap metal, a poor vehicle registration system, weak legislation and the growth of cheap second-hand vehicles all contributed to an increase in the amount of abandoned vehicles. [3]

The recycling, recovery and reuse of ELVs have already raised worldwide concerns. Various nations have implemented different strategies to deal with the issues which vary considerably in severity $[2,4-7]$.

As product-take-back and legislation requirements on producer responsibility are implemented, the use of recycled materials is increasingly important [8].

In the EU, to ensure end-of-life vehicles are disposed of properly, ELV legislations and Environmental Permitting Regulations require all vehicles to be taken to Authorised Treatment Facilities (ATFs) for depollution, dismantlement and deregistration. A 
Certificate of Destruction (COD) will be issued for the last owner of the vehicle after deregistration. Updated information of all the registered ATFs in the UK can be found on Environment Agency's website [9]. Autogreen and Cartakeback are the two major free take-back service providers with ATFs throughout the UK. Within the ATF process, a network of companies cooperates in the recycling process. For example, in the UK, EMR focuses on the scrap metal recycling while sending the plastic rich fraction to their joint venture partners, MBA Polymers Inc, which specialises in separating and recycling different types of polymers.

Figure 1 reviews the general processing procedures of ELVs. The recycling process of a range of separated materials at this stage was detailed in the studies conducted by Baeyens et al. $[10,11]$. The remaining parts pass through a shredder and separation process for ferrous and non-ferrous metals. The resulting residue is termed as Automotive Shredder Residue (ASR), also referred to as 'auto fluff' or 'auto shredder fluff' [12]. Figure 2 illustrates the size and scale of ASR production in Europe in 2008.

\section{Automotive Shredder Residue (ASR)}

Vigano et al. [5] estimated that EU countries produced approximately 1.9-2.3 million tons of ASR annually. This accounted for approximately $10 \%$ of the total number of hazardous wastes produced and up to $60 \%$ of the total shredding wastes [13]. ASR, constituting up to $25 \mathrm{wt} \%$ of the vehicle, is composed of a variety of materials including metal, rubber, wood, dirt, textile, glass and up to 27 different types of plastics, although PP, PUR, PVC, ABS, PMMA and PET are generally identified as the major types $[6,13]$. 
The composition of ASR can differ significantly depending on the shredding and postshredding methods applied.

Since the 1970s, landfill treatment and incineration have been the two major ASR processing methods. Landfill treatment still remains the most widely used method. In some parts of the world, certain measures are required, such as immobilising heavy metals before disposing in landfills. In addition to the environmental problems and ever increasingly stringent legislations, landfill treatment has now become cost-prohibitive and less appealing as an ASR processing method [14].

To meet the European targets for the reuse, recycling and recovery of ELVs set by the EU Directive, research has focused on either more complete dismantling methods or ASR processing techniques. Vermeulen et al. [12] believed that dismantling more materials before shredding is not economically viable in Western countries. This was attributed to the relatively high labour cost (compared to Asian countries) required in the dismantling process. From this point of view, a more efficient disassembly characteristic for future joining technology seems an obvious development. Coates et al. [15] conducted research focusing on both developing design methods to facilitate ELV recovery and current ELV processing economics. Their research highlighted the importance of a shift from manual vehicle dismantling to large volume automated postfragmentation separation in achieving the 2015 target of $95 \%$ recycling set by the EU Directive. 


\subsection{Legislation}

With the ever growing concerns for the recycling of end-of-life vehicles, legislation has developed in many parts of the world. The content below cited examples from Europe, Asia and America to compare and contrast legislations in different regions.

\section{European Union}

So far, the most influential legislation is the ELV Directive 2000/53/EC, which is enacted under the European Commission's priority waste streams program [16]. According to this EU Directive [17], member states must ensure that ELVs are transferred to ATFs and properly recycled. Manufacturers are also encouraged to limit the use of hazardous substances and increase the use of recycled materials in new vehicles. Targets have also been set in different stages:

- From $1^{\text {st }}$ of July, 2003: vehicles put on the market cannot contain lead, mercury, cadmium or hexavalent chromium (materials and components exempted are referred in the annex of the Directive)

- From $1^{\text {st }}$ of January, 2006: reuse and recovery of a minimum of $85 \%$ per vehicle on average (recycling $80 \%$ ) for vehicles produced after 1980; reuse and recovery of 75\% per vehicle on average (recycling 70\%) for vehicles produced before 1980

- From $1^{\text {st }}$ of January, 2015: increase the reuse and recovery rate to $95 \%$ while the reuse and recycling rate to $85 \%$.

Other major legislations that can affect the disposal of shredder residues in EU include: 
a) Directive $2000 / 76 /$ EC on the incineration of waste

b) Directive $1999 / 31 /$ EC on the disposal of waste in landfills

c) Registration, Evaluation, Authorisation, and Restriction of Chemical Substances Directive (REACH)

d) Environmental Permitting (England and Wales) Regulations SI 2010/675 on environmental permits and exemptions.

\section{Asia}

In Japan, the End-of-Life Vehicles recycling law, prompted by limited natural resource and land resource for landfill sites, was introduced in 2005 [18, 19]. It is similar to the EU counterpart but extended to cover virtually all vehicles; the EU directive is restricted to passenger vehicles and light commercial vans only [2]. The law stipulated that it is the automakers' responsibility to provide dismantling manuals whilst vehicle owners will be charged for the treatment of ELVs.

In South Korea, the Act for Resource Recycling of Electrical and Electronic Equipment and Vehicles offers the scheme for both the manufacturers and importers in terms of the restrictions on hazardous substances (from $1^{\text {st }}$ July, 2008), recycling rates, design and methods recycling, etc. [20] Unlike the EU directive, this Act does not address the recycling issues of tyres, batteries or air bags.

In China, Statute 307 regulates the disposal of ELVs in China. In 2001, the State Council of the People's Republic of China enacted the 'End-of-Life Vehicle Recycling Regulation', 
i.e. the Statute 307, which stipulates the responsibilities of local government and ELV recycling industry regarding registration capital and capacity of dismantling activities [21].

The Automotive Products Recycling Technology Policy [22] was enacted by the National Development and Reform Commission (NDRC) in 2006 aiming at establishing the ELV recycling system, including developing and promoting scrapped automotive products [2]. However, the enforcement was comparatively weak compared with Korea and Japan. This policy established a minimum of $85 \%$ reuse and recovery target by 2010 . The use of hazardous chemicals such as lead, cadmium, hexavalent chromium and mercury is prohibited.

\section{America}

In the United States, no legislation has been developed on a federal level to address ELV recycling issues even though attempts have been made by some senators since 1991 . The main argument appears to be that enacting legislations are not considered an effective method to improve recycling [19].

Instead, large manufacturers in the USA have shared this responsibility. In 1992, Ford, Chrysler and General Motors initiated a Vehicle Recycling Partnership to facilitate sustainable vehicle recycling both in North America and around the world [16]. Another term often referred to in the USA is 'Product Stewardship' which means every party 
involved in the lifespan of product share the responsibility for reducing its environmental impact.

\subsection{Recycling issues for future vehicles}

Due to the depletion of natural resources and exacerbating environmental issues, fuel efficiency and $\mathrm{CO}_{2}$ emission are two major concerns. One effective approach to these problems is to reduce vehicle weight due to the fact that approximately $75 \%$ of fuel consumption is caused by vehicle weight [23]. For example, a $100 \mathrm{~kg}$ reduction in weight could save $0.4 \mathrm{l} / 100 \mathrm{~km}$ fuel consumption.

Engines, running gears, and chassis frames, among other components, have been increasingly made of lightweight metals [24]. Low-weight, cost-effectiveness, production times, ease of installation are expected to be some of the key features for future automotive vehicle components. OEMs today have intensified their efforts in using lightweight materials such as polymers and composites, as substitutes of ferrous materials. Figure 3 shows the change of material use in automotive vehicles from 1977 to 2011. In more recent years, government initiatives, safety issues, increased demands of return on capital further facilitate the development of composite materials for future vehicles [25].

Waste management and environmental legislations now require higher rates of reuse, recycling and recovery. However, the use of polymer and composite materials 
complicates the recycling process. This is one of the main obstacles to the wide spread application and acceptance of lightweight materials in the automotive sector.

This difficulty can be explained from two aspects. Firstly, to separate composites and polymers from metals can be labour-intensive and expensive. Even though the industry has made significant progress on recycling technology [19], the shift to lightweight material makes it more challenging. The main joining technique for polymers and composites is adhesive bonding as it generally outperforms traditional joining technologies when joining dissimilar materials and non-metal materials but it incurs more problems during the recycling process of end-of-life products.

Secondly, the recycling and recovering process of composite materials, due to their physical and chemical makeup, is difficult. The recycling of fibre constituents in some fibre reinforced composite has been a source of heated debate [26, 27] Facing the recycling challenges, many have suggested that design for disassembly is now an essential requirement of the design process [28]. Specifically, a new joining technology that enables rapid disassembly is of great interest. 


\section{Adhesive Bonding in Automotive Industry}

The automotive industry is facing challenges of joining dissimilar materials while maintaining mechanical properties and durability, especially in structural applications. Adhesive bonding is now extensively considered to be the replacement of conventional joining methods such as riveting, bolting and welding. Here is a list of major advantages:

a) All solids can be joined including combinations of dissimilar materials, although pre-treatment may be necessary.

b) More uniform distribution of stress and increased fatigue life

c) Weight savings

d) Corrosion between dissimilar materials can be prevented or reduced

e) Films and thin sheets can be bonded

f) Delicate parts such as electronic components can be joined

g) Relatively high impact resistance

The applications of adhesive bonding in car body joining can be subdivided into four main functions: sealants for body joints, spot-welding sealants and tapes, antiflutter bonding, and structural adhesive bonding and hem flange sealing [29]. For structural application, the combination of spot welding and adhesive bonding achieves a more efficient connection. For example, in comparison with the stiffness of a spot welded structure, adhesive bonding can offer 15 to $30 \%$ enhancement [30]. Also, for a boxbeam bonding application, research conducted by Henkel showed that the use of an 
impact resistant structural adhesive resulted in an approximately $30 \%$ increase of energy absorption compared to a spot-welded structure. [31]

Anti-flutter adhesives are applied in the form of soft elastic joints between the inner and outer panels on bonnets or sides to add the stiffness and dampen the effect of vibration and noise. A relatively low shrinkage and low modulus are always required for antiflutter adhesives to compensate for tolerances after filling up gaps between components [30].

Body joint sealing adhesives behave as sealants and are normally applied after the assembly process in order to protect components from the influence of dust, water and other factors which could induce corrosion [32]. Typical sealant types used in the body shop are acrylic esters, epoxies, polybutadienes, polyurethanes and PVC/epoxy blends. These adhesives have to go through a curing process in an electro-coat oven. Consequently, this requires the handling strength of the body to be supplemented by joining techniques such as spot welding. Acrylic plastisols, reactive butyls, and nonsetting rubber compounds are widely used in this area [33].

\section{Case Study 1: Adhesives in automotive interiors.}

Adhesives are employed in automotive interior applications both for improved performance and for aesthetic design. Generally, reactive hot-melt adhesives are used with efficient robotic application because of their resistance to extreme temperatures ($40^{\circ} \mathrm{C}$ to $125^{\circ} \mathrm{C}$ ) and the ability to achieve a green strength in a short period. For specific 
uses like lamp assembly and spare-tyre cover lamination, two-part epoxy adhesives and silicone adhesives are usually used [34, 35]. Since load bearing is not essential for the internal trims, ease of handling and assembly often determine the use of adhesives in this application. For instance, pressure sensitive adhesives in the form of two-side tapes are used to attach labels and decals [35].

\section{Case Study 2: Adhesive bonding for space frames.}

An emerging application for adhesives in body assembly is the construction of the space frame. Over the past decades, adhesively bonded space frames including box-beam structure have been employed by a number of car manufacturers in concept cars and low volume models (e.g. Jaguar XJ220, Ford AIV, Lotus Elise and Aston Martin Vanquish) [36-38]. The relatively demanding mechanical property requirements for this major structural component necessitate the application of high quality adhesive bonds. Hence, both a part pre-treatment process and high performance adhesives are typically used $[36,37]$. For example, the production of the Lotus Elise space frame utilizes both an anodizing process for the extruded aluminum components and a high performance single part heat cured epoxy (with tensile strength of around 35MPa and Young's modulus of about $2700 \mathrm{MPa}$ ) to achieve its desired properties [38].

The use of adhesives in space frame construction brings a number of benefits. One of the most significant ones is to fully extract the strength-to-weight benefits offered by the light weight aluminum alloys which cannot be easily welded without losing properties $[37,38]$. The $68 \mathrm{~kg}$ adhesively bonded space frame of the Lotus Elise achieved 
an astonishing $50 \%$ weight reduction compared with an equivalent steel construction bonded with spot welding [38]. Compared with welding techniques, adhesive bonding also provides higher precision of the space frame structure due to the elimination of distortion that comes with the localised high temperature zone [31, 38]. This is highly valued in high performance car structures because even tiny distortions $(0.5 \mathrm{~mm})$ to the space frame can affect the handling of the vehicle [39]. Together with other typical advantages brought by adhesive bonding, the adhesively bonded automotive space frame has fully demonstrated its merits over the past decades.

However disadvantages also exist in an adhesively bonded automotive space frame. The limited production rate caused by the time consuming curing and joining processes is one of the major concerns. Recent developments in robotic and curing facilities has achieved a production rate of about 3000 units per annum for a hybrid adhesively bonded space frame, however further developments are still needed for higher production volume $[37,38,40]$. Also, the difficulties for maintenance and repairing should not be ignored. If an adhesively bonded space frame is damaged in an accident, it cannot be repaired using conventional techniques as with a steel chassis. Replacement of the whole space frame may occur under serious collision $[36,38,41]$.

\section{Case Study 3: Automotive Front End Module (FEM).}

The front end module supports the cooling package, bonnet latch mechanism, headlights, bumper and many other components. The major requirements for the FEM include crashworthiness, thermal and chemical stability, and durability. Polymer metal 
hybrids (PMHs) technology has gained popularity in making automotive FEMs in recent years. The Lanxess group has been developing PMHs technologies for many automakers [42]. BMW, in its 1, 3 and X3 series, the new Audi TT and Audi A8 employed the Lanxess' technology to produce front end modules $[43,44]$. PMHs have been introduced as an approach to meet both structural and non-structural requirements while at the same time achieving a lightweight structure.

In addition to injection over-moulding and metal over-moulding technologies, adhesive bonding is another major approach to manufacture PMHs in the automotive industry $[45,46]$.

Adhesively bonded PMHs technologies were first introduced and patented by Dow Automotive in 2003. Dow developed a low energy surface adhesive to bond glass-fibre reinforced polypropylene to a metal stamping [47]. Compared to traditional hybrid front end manufacturing such as rivet bonding and over-moulding, adhesive bonding improves the stiffness and minimises stress concentration by forming a continuous joint along the plastic to metal interface [48]. However, from an ELV recycling point of view, to separate polymers from metals in this adhesively bonded hybrid can be laborious and costly. Consequently, a method of rapid disassembly would be highly desirable. 


\section{Adhesive Disassembly Technology and Recent Advances.}

\section{General methods for adhesive bonding disassembly}

Previous research [49] conducted within the Joining Technology Research Centre (JTRC) at Oxford Brookes University has summarised methods for disassembly of adhesive joints from various areas. The approaches for general adhesive bonding and novel methods have been covered to a large extent.

The mechanical separation method of disbonding was identified as the most primitive approach. A range of patented works [50-53] have attempted to the assist disassembly process, yet there is a lack of clean separation of the substrates and the method is generally inefficient and laborious.

Thermally induced disassembly approaches can be achieved through both thermal softening (exceeding the adhesive's $\mathrm{Tg}$ ) and thermal decomposition (exceeding the temperature of flammability-in-air or auto-ignition point). For the latter, the major concerns are the toxic and irritant emission gases that are produced as a result of chemical decomposition [5]. Table 1 shows the reaction products determined after isothermal degradation.

Certain solvent or acid immersion techniques can also assist the adhesive disassembly process. Polar solvents such as isopropyl alcohol (IPA), methyl ethyl ketone (MEK) and acetone, can be very effective in cleaning and degreasing substrate surfaces and are mainly used in surface treatment processes $[55,56]$. 


\section{Tailored adhesive formulations for the ease of adhesive disassembly}

To a large extent, the electronic chip industry started the research for disassembly on adhesive formulations to enable rapid removal of chips at end of life [57-59]. Different approaches have been developed in different areas. Battelle Memorial Institute [60] developed a thermally reversible isocyanate-based polymer formulation, the reversibility mechanism of which was based on the dissociation of the isocyanate-labile hydrogen based linkage to the isocyanate and labile-hydrogen starting groups. Upon disassociation, this polymer was found to become a free flowing melt, which was soluble in acids. Atochem [61] and Yokohama [62] used different chemistries in their research but achieved a similar system.

Sandia National Laboratories [63] developed a thermally removable adhesive by incorporating thermally reversible furan-maleimide Diels-Alder adducts (which form below $60{ }^{\circ} \mathrm{C}$ and dissociate above $90^{\circ} \mathrm{C}$ ) to a low modulus epoxy adhesive formulation, Figure 4. However, experimental data in their research demonstrated only fairly weak lap shear strengths (between 3.36 and 4.65 MPa), which cannot be used for structural application. Also, the relatively low dissociation temperature rules out its use for many applications. This reversible Diels-Alder adduct has however drawn much attention and its properties were further investigated in recent research conducted by Claudio et al. [64].

The DC Polymers [65] adopted electrochemically active cross-linkers, which can be incorporated into the polymer structure. Electrochemical reduction can be triggered by 
applying an electric current. This leads to scission of the polymer backbone at crosslinker sites and thereby polymer degradation. Since crosslinking is quite common to all types of polymers, this technology can be theoretically applied to a wide range of polymeric materials. However, this technology is still restricted to preliminary studies and no mature product or experimental data has been published.

Developed by EIC Laboratories and one of the most prominent and elaborate systems to date, ElectRelease is the trade name for a series of structural epoxy adhesives which can be dismantled quite easily by applying an electric current at 10-50V, Figure 5 . The disbonding mechanism is achieved through ion conduction along the resin-metal interface. Pseudo-micelles are formed by incorporating a nanoscaled backbone blocks of polydimethylsiloxane(PDMS) into a two-part amine-cured epoxy resin structure. The backbone structure is also attached to the arms of polyethylene glycol (PEG) which creates a comb-type polymer and pseudo-micelles structure in the uncured epoxy resin. Upon curing, the PEG micelle phase separates from the epoxy around the immiscible PDMS cores and forms a nano scaled co-continuous network, Figure 5. High level ionic conductivity can be further achieved through post-treatment with suitable salts. [66]

The disbonding needs a metal as the positive substrate and another suitable material for the negative substrate. When two metal substrates are bonded using ElectRelease, disbonding at both interfaces can be achieved by reversing the polarity of the disbonding voltage. For non-conductive materials, an ElectRelease foil patch (EFP) which 
is essentially two sheets of metal foil, is applied on the surface to enable electric conductivity. [67]

The ionic conductivity determines the effectiveness of the disassembly process. However, epoxy resins normally have a relatively low ionic conductivity and high ionic conductivity polymers are typically in a rubbery or gel-like state. This is one of the reasons why EIC Laboratories adopted a nano-scaled block copolymer to modify the ionic conductivity while at the same time retaining the epoxy resin structure and therefore strength [49].

The development of ElectRelease technology has triggered intense interest in investigating electrically assisted disbonding adhesive formulations. Simon et al. [68] investigated the ElectRelease technology and provided further understanding of the disbonding mechanisms. They observed a delamination process at the interface between the aluminium anode and the adhesive layer, detected the changes in polymer chemistry using Raman spectroscopy and also analysed the emission of volatile species using mass spectrometry. Four delamination mechanisms were proposed and discussed.

\section{Functional additives for the ease of adhesive disassembly}

There are numerous research papers and patents in the literature on incorporating certain additives or agents to trigger the debonding process. One of the earliest examples was patented [69] by shoe manufacturers for separating shoe soles from uppers. The debonding process was achieved by incorporating metallic inclusions into 
the adhesive to efficiently absorb and emit heat energy when subjected to alternating electro-magnetic field thereby activating the release of micro-encapsulated solvents, which would further degrade the polymeric structure. Probably influenced by this idea, Daimler-Chrysler and partners [70] patented similar work and specified examples of encapsulated solvents as organic amines or acids which can cleave an epoxide backbone. Microcapsules were recommended to be made of amino resin or metal halide. Obediat [71] reviewed recent patented works of different microcapsule preparation methods used in the field of pharmaceutical. Work patented by the Nissan Motor Company [72] mixed oxidising agents (ammonium perchlorate, potassium permanganate, etc.) into the adhesive matrix which produced a self-burning reaction at elevated temperatures. The decomposition process generated abundant oxygen and caused failures in the bondline. However, the volatile nature of these oxidising agents is one of the major concerns for its application in automotive industry.

These approaches lay the foundation for many more recent and influential studies. Chemical foaming agents (CFAs) and thermally expandable additives have drawn most attention.

Henkel [73], IBM [74], US Army Research Laboratory [75] and Rescoll [76, 77] investigated a series of CFAs including Azo compounds, and hydrazides. Different types of foaming agents were incorporated into adhesive systems to assist the disassembly process at elevated temperatures. Interestingly, Rescoll's research noted that CFAs would become mobilised at higher temperatures when the adhesive bondline softened 
and melted. Some CFA particles or microspheres would then migrate and finally decompose at the joint interface.

Research in the Joining Technology Research Centre (JTRC) at Oxford Brookes University [49] investigated the effect of the incorporation of functional additives on the dismantling characteristics of three vehicle OEM approved adhesives: two fracture toughened epoxies and one semi-structural polyurethane. The functional additives selected were four types of chemical foaming agents (CFA): $p$-toluenesulfonyl hydrazide (pTSH), benzenesulfonyl hydrazide (BSH), azodicarboxamide (ADC) and 5-phenyl-1Htetrazole $(5 \mathrm{P} 1 \mathrm{HT})$. No discernible benefit was observed from the experimental data of CFA incorporated into the semi structural adhesive. However, the structural adhesive systems were found to be promising but still showed problems of additive/adhesive incompatibility, which therefore affected the long-term durability. More importantly, additive-matrix incompatibility issues were pointed out in this research.

In terms of thermally expandable additives, an early work patented by $3 \mathrm{M}$ [78] used inorganic materials such as dilated graphite, vermiculite, pearlite or mica as expanding additives. The expandable additive content was generally specified as 10 to $50 \mathrm{wt} \%$. Initiation temperature was reported to be $250^{\circ} \mathrm{C}$ to $500^{\circ} \mathrm{C}$ with expansion ratio normally 1.1. It is also claimed that these additives could enhance the heat resistance of an adhesive. However, neither experimental data nor any convincing proof was disclosed.

Expandable additives have also been used for adhesive disassembly in orthodontic application. The removal of orthodontic attachments has great risk of causing enamel 
damage if mechanical separation is undertaken improperly. The use of electrothermal, laser or ultrasonic methods may incur other problems such as expensive equipment cost, potential pulpal damage and mucosal burns [79, 80]. Tsuruoka et al. [81] incorporated thermally expandable microspheres (TEMs) into 4-META/MMA-TBB (4methacryloxyethyl trimellitate anhydride in methyl methacrylate initiated by tri-n-butyl borane) resin adhesive, which is widely used for bonding orthodontic brackets. The microspheres used in this study were Matsumoto F-36D which starts to expand at $80^{\circ} \mathrm{C}$. They identified that an incorporation of $40 \mathrm{wt} \%$ of these microspheres showed satisfactory bond strength before heating and a reduced bond strength by a third within 8s of heating. The Tokyo Institute of Technology $[82,83]$ also conducted research on adhesive disassembly using expanding microspheres manufactured by Matsumoto. These studies also looked at its application for construction materials. The weight fraction of microspheres used and the roughness of adherend surfaces were found to be two major factors in determining the dismantalability of the bonded joints.

Thermally expandable microspheres are generally constructed with a thermoplastic polymer shell and hydrocarbon core, which has a low boiling temperature. The density reduces from about $1100 \mathrm{~kg} / \mathrm{m}^{3}$ to $30 \mathrm{~kg} / \mathrm{m}^{3}$ at elevated temperature [84]. TEMs were first developed by Dow Chemical Co. and currently are being manufactured by many companies such as Polychem Alloy, Sekisui Chemical, Matsumoto Yushi Seiyaku, Akzo Nobel and Sigma Aldrich. JTRC's research also investigated four different grades of physical foaming agents (TEMs) containing isobutene, isooctane or isopentane. These 
selected grades of additives provide a range of activation temperatures and decomposition/expansion efficiencies.

The Army Research Laboratory [75] has investigated a reactive nanocomposite (RNC) approach to solve a rapid disassembly problem. The disassembly is thermally triggered and a physical change occurs as an additional interface is required for the RNC to be inserted into the bondline. However, no further information was disclosed.

Reviewing most of these current studies on functional additives, it is noted that none of the approaches mentioned create a system sufficiently effective for the disassembly of an adhesive application in the automotive industry. Disassembly efficiency and additivematrix compatibility were identified to be two major concerns, which were either vaguely mentioned or completely neglected in most patented works. Some studies have identified these problems to be main obstacles but failed to provide a feasible solution. JTRC's research had identified additive-matrix incompatibility and noted that the incorporation of additives affect mechanical properties and durability by acting as weak links in the matrix, or in some cases, reacting with the matrix. Magnus et al. [84] successfully modified TEMs by grafting glycidyl methacrylate (GMA) on the surface. Atom transfer radical polymerization using activators regenerated by electron transfer (ARGET ATRP) was employed. Special treatment was also used to retain the expansion ratio of the TEMs.

De-Bonding Ltd and Evonik have focused on developing a system with efficient disassembly processes. The research of De-Bonding Ltd has looked at the dismantling of 
automotive glazing on ELV by incorporating TEMs in the adhesive bondline [85-87]. In cooperation with the Armes group at Sheffield University, their research [88] has successfully synthesised polypyrrole-coated TEMs which are only microns in size. The research investigated the effect of the TEMs on the delamination of the adhesive joints. An infra-red lamp was adopted as the heating source. Polypyrrole has a broad absorption peak (900-1500 nm) in the infra-red. This provides the polypyrrole-coated TEMs with a very efficient thermal energy absorbance. Experimental results showed great potential for the application of reversible adhesion of car glazing and panels for both maintenance and recycling purposes.

Evonik [89] developed a type of adhesive tape called Magsilica. Magsilica is used as a nano susceptor which is basically a powder of iron oxide particles embedded in silicon dioxide nanoparticles. These particles behave as nano magnets when subjected to external magnetic field, which can heat up for the purpose of curing and disassembly. This has achieved two major advantages: shortened cure times and reversible bonding. Evonik has patented their work and showed several examples for its use [90]. A major concern is that conductive or magnetic components can cause electromagnetic shielding, which deactivates the heating mechanism. McCurdy in JTRC [49] attempted to replicate the dismantling characteristics on a toughened epoxy adhesive incorporated with MagSilica powder. Half size single lap joints (ISO 4587) were made from $2 \mathrm{~mm}$ thick steel substrate with a $0.2 \mathrm{~mm}$ adhesive bondline thickness. An induction heating method was adopted and a temperature of $120^{\circ} \mathrm{C}$ (above epoxy resin $\mathrm{Tg}$ ) was used to lead to debonding within 30s. However, no satisfactory material separation was recorded. 
Reasons were attributed to the ineffectiveness of direct induction heating which led to large residue strength of structural adhesive.

\section{Other relevant advances}

The addition of functional additives into adhesives can potentially influence certain adhesive properties. The University of Pennsylvania and Loughborough University [91] have both conducted research on the addition of carbon nanotubes (CNTs) into conventional epoxy. Thermal conductivity, mechanical properties, heat resistance and long term durability were all seen to increase significantly with even a small concentration of CNTs. Graphene technology, with lower production cost compared with CNTs was also seen to have similar effect [92]. It is the author's opinion that by incorporating CNTs or grapheme into the adhesive, the improvement in thermal conductivity could enhance the disassembly efficiency as heat could be transferred to functional additives much faster. Also, the mechanical properties and durability could be compensated to a large extent. Lumia Adhesives developed Adhelight [93], which maintains strong adhesion but loses most strength within 15 seconds when exposed to light. $0.05 \%$ to $10 \%$ of photoinitiator was normally incorporated into the adhesive matrix. This technology was developed for medical skin applications. Sunny et al. [94] synthesised micro-patterned carbon nanotube-based tapes which was inspired by the hierarchical hairy structure of a gecko foot. This technology has formed the basis of a new class of adhesive which adapts to a continuous bonding and debonding process. 
A comparison and overall rating of all disbonding techniques discussed in this paper can be found in Table 2. The incorporation of thermally expandable microspheres or chemical foaming agents into current commercial adhesive system both achieve the highest rating (four stars) in the table. Currently their automotive applicability is limited mainly by their compatibility with adhesive matrix. However, the chemical foaming agents react with the adhesive matrix and change its chemical structure whereas thermally expandable microspheres only act as weak physical link. The authors believe that the thermally expandable microspheres approach has more potential for automotive applications. 


\section{Conclusions and Outlooks}

The ELV situation, ELV legislation and future vehicle recycling concerns all necessitate the development of a new joining solution(s), which assists the rapid disassembly of components for repair and maintenance scenarios. Below is a summary of the key findings:

- Adhesive bonding outperforms conventional joining solutions, particularly where multi-material assemblies are concerned. However, one of their main limitations is their poor disassembly efficiency;

- Innovations in adhesive disassembly technology have been thoroughly reviewed for their application in many different industry sectors; Tailored adhesive formulation and functional additives were identified to be the two major routes for adhesive disassembly technology;

- The functional additives approach (such as chemical foaming agents, oxidising agents, thermally expandable microspheres) has generally received more attention because they can be introduced into existing adhesive products;

- Functional additive/adhesive compatibility and disbonding efficiency have been identified as the two major problems concerning functional additives. 
Table 1. Volatile Compounds of Isothermal Degradation of Epoxy Resin [95].

\begin{tabular}{|c|c|c|c|c|c|}
\hline Compound & $\begin{array}{c}1 \text { hour at } \\
220^{\circ} \mathrm{C}\end{array}$ & $\begin{array}{c}1 \text { hour at } \\
280^{\circ} \mathrm{C}\end{array}$ & $\begin{array}{c}1 \text { hour at } \\
300^{\circ} \mathrm{C}\end{array}$ & $\begin{array}{c}1 \text { hour at } \\
320^{\circ} \mathrm{C}\end{array}$ & $\begin{array}{c}1 \text { hour at } \\
340^{\circ} \mathrm{C}\end{array}$ \\
\hline $\mathrm{CH} 4$ & 0 & 0 & Trace & $* *$ & $* *$ \\
\hline $\mathrm{CO}$ & 0 & 0 & 0 & * & * \\
\hline $\mathrm{CO} 2$ & \multicolumn{3}{|c|}{$\begin{array}{l}\text { Too small for positive identification } \\
\qquad\left(220^{\circ} \mathrm{C}-300^{\circ} \mathrm{C}\right)\end{array}$} & trace & $*$ \\
\hline Propylene & \multicolumn{5}{|c|}{ Too small for positive identification $\left(220^{\circ} \mathrm{C}-340^{\circ} \mathrm{C}\right)$} \\
\hline Formaldehyde & \multicolumn{5}{|c|}{ Suspected but too small for positive identification $\left(220^{\circ} \mathrm{C}-340^{\circ} \mathrm{C}\right)$} \\
\hline Acrolein & Trace & $* *$ & $* * *$ & $* * * *$ & $* * * *$ \\
\hline Acetone & Trace & * & $* *$ & $* * *$ & $* * *$ \\
\hline Allyl Alcohol & Trace & $*$ & $* *$ & $* * *$ & $* * *$ \\
\hline Water & $* *$ & $* * *$ & $* * * *$ & $* * * * *$ & $* * * * * *$ \\
\hline
\end{tabular}

The number of asterisks is a qualitative indication of the relative amounts of products. 
Table 2. Comparison and Rating of Disbonding Techniques.

\begin{tabular}{|c|c|c|c|c|c|c|}
\hline Techniques & Disbonding Condition & $\begin{array}{c}\text { Automotive } \\
\text { Applicability }\end{array}$ & Complexity & $\begin{array}{c}\text { Capital } \\
\text { Cost }\end{array}$ & $\begin{array}{c}\text { Disbonding } \\
\text { Efficiency }\end{array}$ & $\begin{array}{l}\text { Overall } \\
\text { Rating* }\end{array}$ \\
\hline Mechanical separation & $\mathrm{N} / \mathrm{A}$ & Low & Low & Low & Low & $*$ \\
\hline Thermally reversible structure & Temperature $\left(100-250^{\circ} \mathrm{C}\right)$ & Low & High & Medium & Medium & $* *$ \\
\hline Thermally removable adhesive & Temperature $\left(90^{\circ} \mathrm{C}\right)$ & Low & High & Medium & Medium & $* *$ \\
\hline Electrochemically reversible structure & Electric Current (not specified) & N/A & High & High & $\mathrm{N} / \mathrm{A}$ & $* *$ \\
\hline Ionically conducting epoxy adhesive & Electric Current (10-50V) & Medium & High & High & High & $* * *$ \\
\hline Oxidising agents & Temperature $\left(300^{\circ} \mathrm{C}\right)$ & Low & Medium & Medium & Medium & $* *$ \\
\hline Microcapsules & Temperature $\left(175^{\circ} \mathrm{C}\right)$ & Low & High & Medium & Medium & $* *$ \\
\hline Thermally expandable additives & Temperature $\left(250-500^{\circ} \mathrm{C}\right)$ & Low & Medium & Medium & Medium & $* *$ \\
\hline Chemical foaming agents (CFAs) & Temperature $\left(130-250^{\circ} \mathrm{C}\right)$ & Medium & Medium & Medium & High & $* * * *$ \\
\hline Thermally expandable microspheres (TEMs) & Temperature $\left(120-200^{\circ} \mathrm{C}\right)$ & Medium & Medium & Medium & High & $* * * *$ \\
\hline Light sensitive switchable adhesive & Exposure to light (20 seconds) & Low & High & High & High & $* *$ \\
\hline Gecko inspired nano-structured adhesive & $\mathrm{N} / \mathrm{A}$ & Low & High & High & High & $* *$ \\
\hline
\end{tabular}

*Overall Rating: $1^{*}$ to $5^{*}$ from low to high rates. 


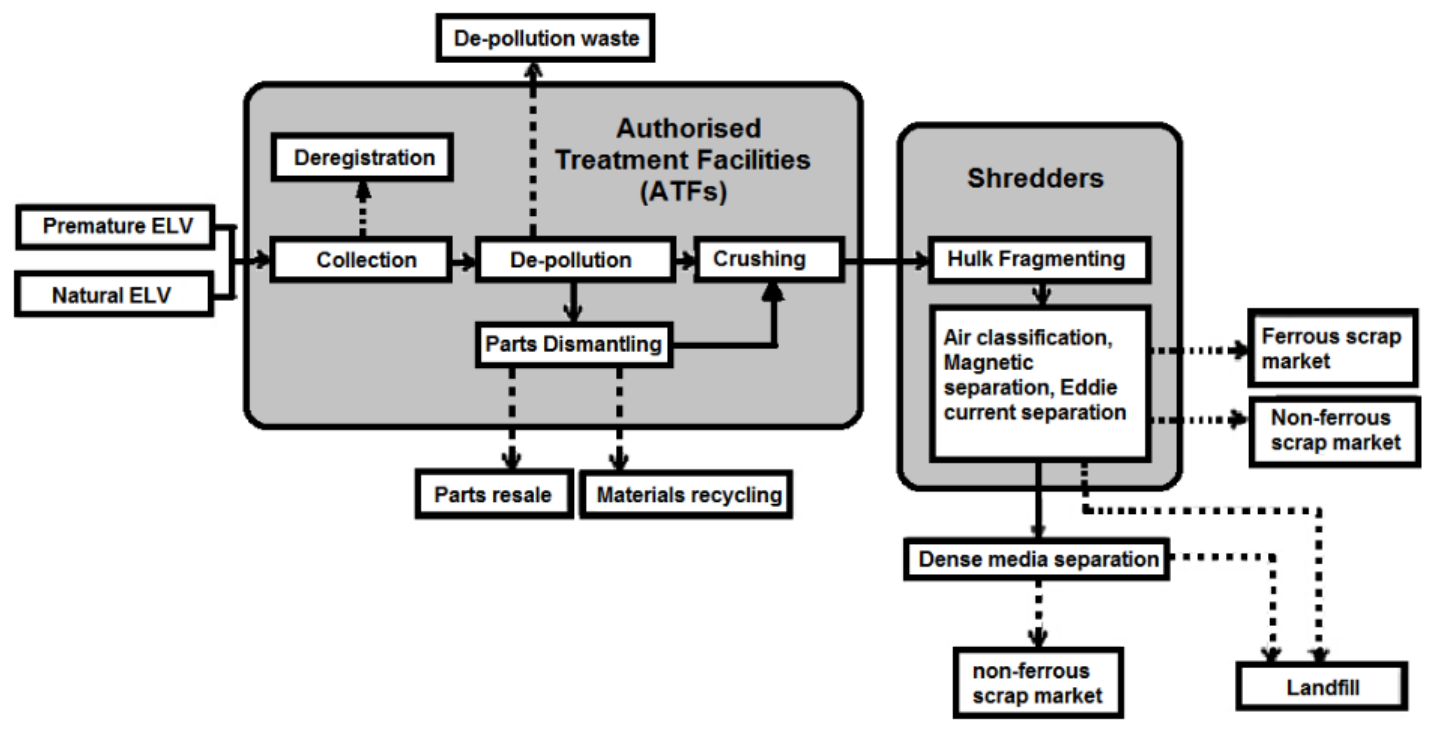

Figure 1. Flow of a vehicle through the different end-of-life operations. [96]

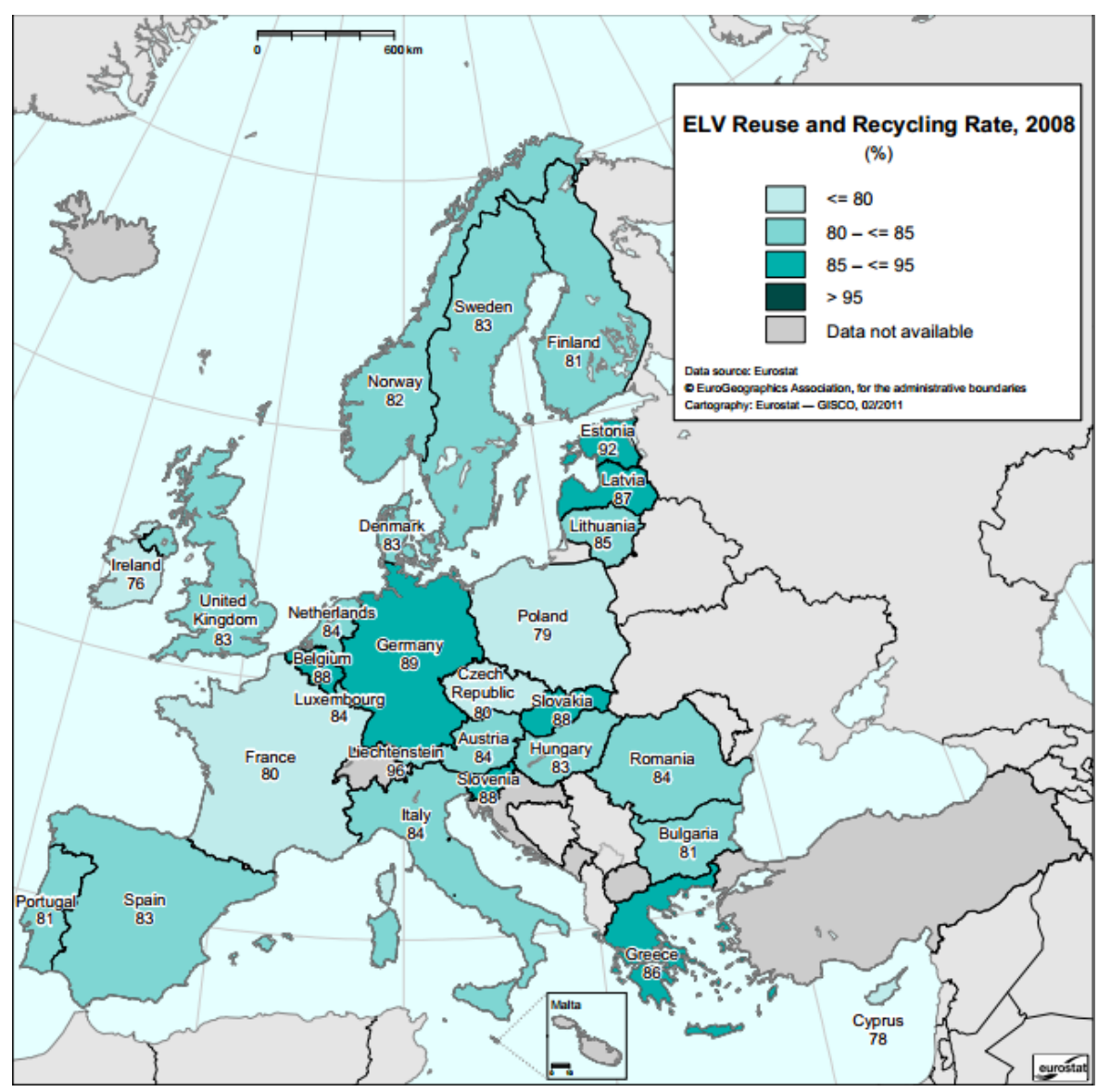

Figure 2. The recycling and recovery rate of ELVs at European Union in 2008. [97] 


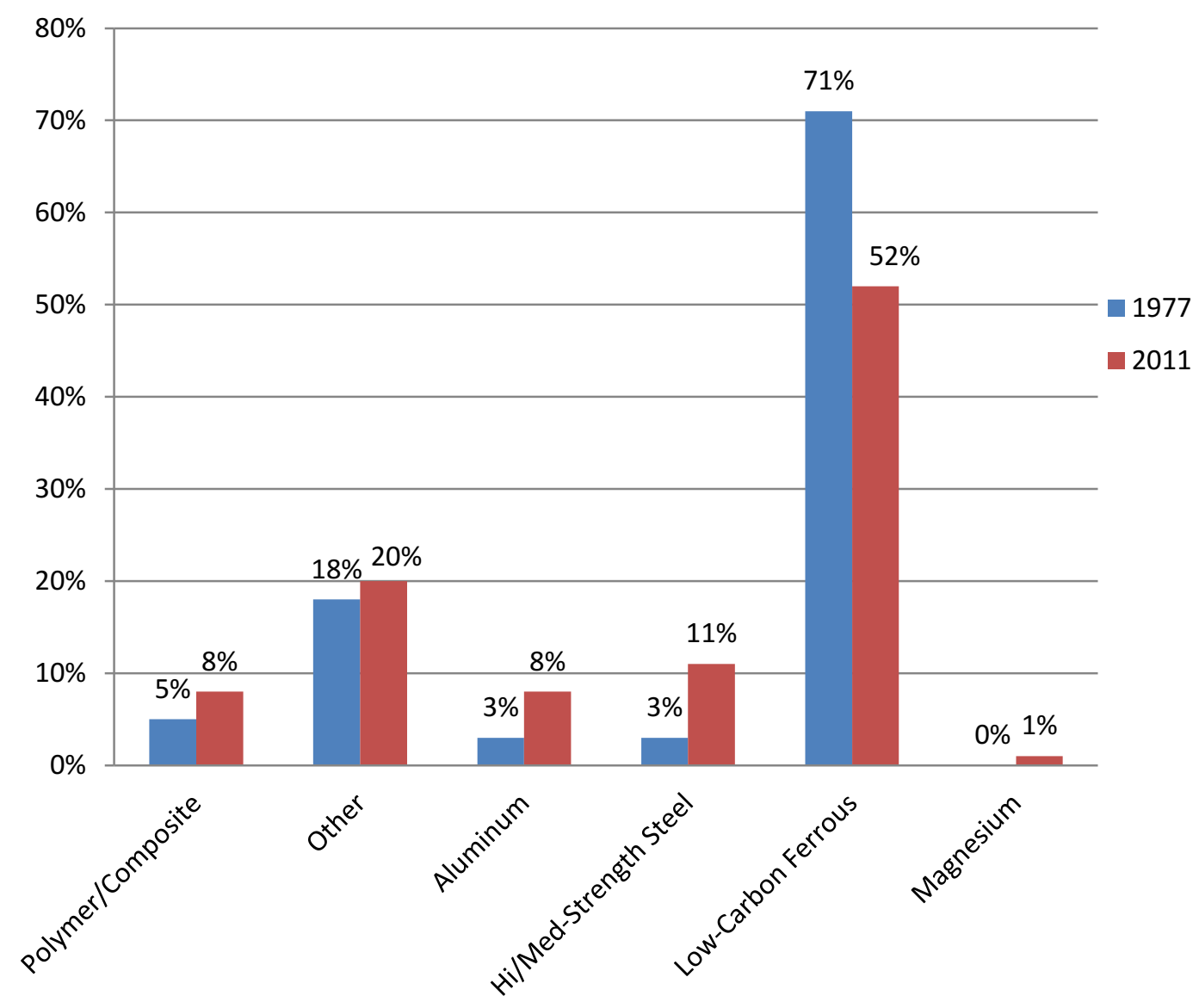

Figure 3. Material use in automotive vehicles from 1977 to 2011. [98]

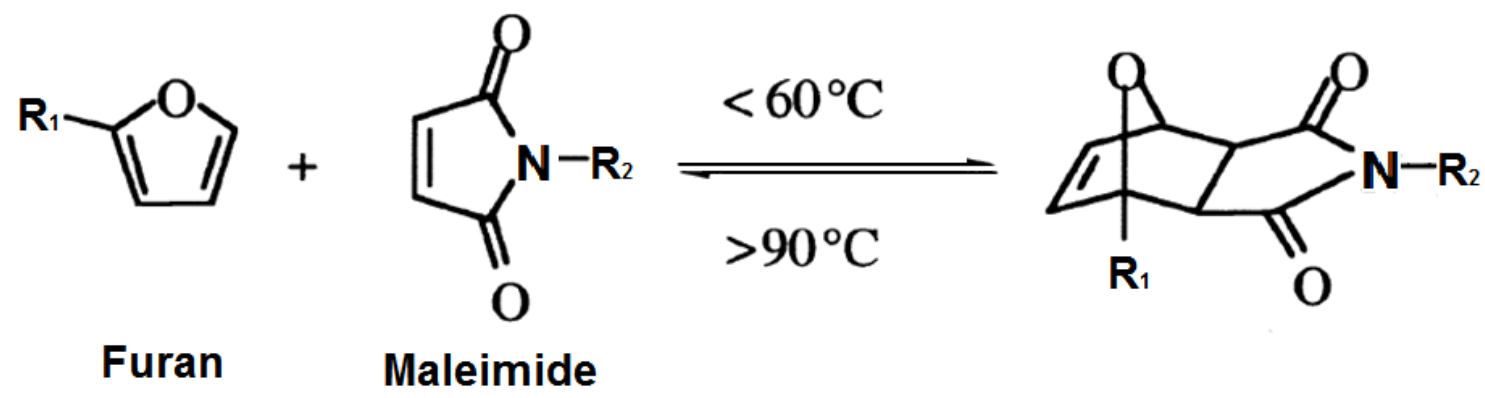

Figure 4. Reversible Diels-Alder reaction between furan and maleimide. 


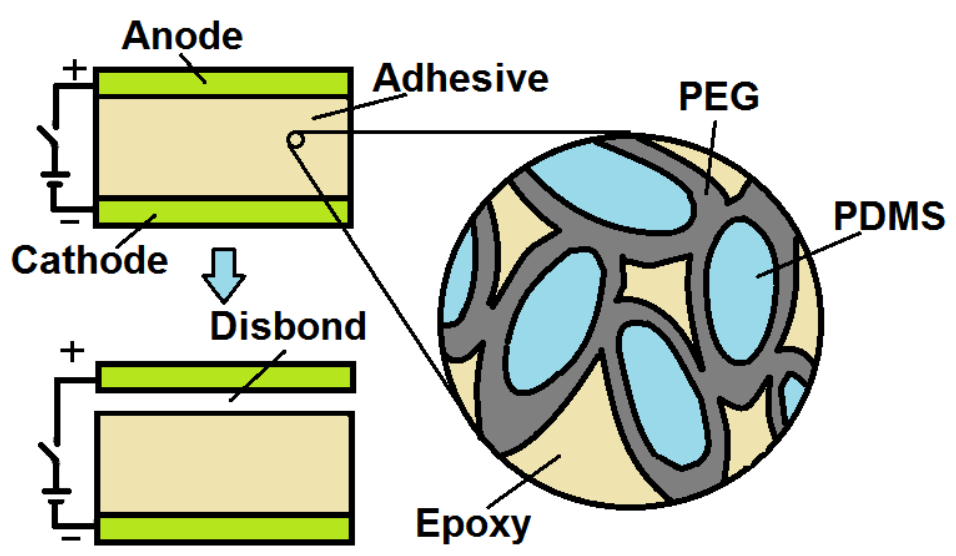

Figure 5. Microscopic structure of ElectRelease. [66]

\section{References}

1. International Organization of Motor Vehicle Manufacturers. http://oica.net/wpcontent/uploads/press-release-press-conference-2013-03-06-_v3b_.pdf.

2. Q. Zhao, M. Chen, A Comparison of ELV recycling system in China and Japan and China's strategies, Resour Conserv Recycl, 57, 2011, 15-21.

3. M. Smith, J. Jacobson, B. Webb, Abandoned vehicles in England: impact of the end of life directive and new initiatives, on likely future trends, Resour Conserv Recycl, 41, 2004, 177-189.

4. A. Santini, L. Morselli, F. Passarini, I. Vassura, S. D. Carlo, End-of-Life Vehicles management: Italian material and energy recovery efficiency, Waste Manag, 31, 2011, 489-494. 
5. F. Viganò, S. Consonni, M. Grosso, L. Rigamonti, Material and energy recovery from Automotive Shredded Residues (ASR) via sequential gasification and combustion, Waste Manag, 30, 2010, 145-153.

6. K. Kim, H. Joung, H. Nam, Y. Seo, J. H. Hong, T. Yoo, B. Lim, J. Park, Management status of end-of-life vehicles and characteristics of automobile shredder residues in Korea, Waste Manag, 24, 2004, 533-540.

7. C. Zoppi, S. Lai, Assessment of the Regional Landscape Plan of Sardinia (Italy): A participatory-action-research case study type, Land Use Policy, 27(3), 2010, 690-705.

8. T.F. Go, D.A. Wahab, M.N.Ab. Rahman, R. Ramli, C.H. Azhari, Disassemblability of end-of-life vehicle: a critical review of evaluation methods, J Clean Prod, 19(13), 2011, 1536-1546.

9. http://www.environment-agency.gov.uk/business/regulation/65470.aspx.

10. J. Baeyens, A. Brems, R. Dewil, Recovery and recycling of post-consumer waste materials. Part 1. Generalities and target wastes (paper, cardboard and aluminium cans), Int J Sustain Eng, 13(3), 2010, 148-158.

11. J. Baeyens, A. Brems, R. Dewil, Recovery and recycling of post-consumer waste materials Recovery and recycling of post-consumer waste materials. Part 2. Target wastes (glass beverage bottles, plastics, scrap metal and steel cans, end-of-life tyres, batteries and household hazardous waste), Int J Sustain Eng, 3, 2010, 232-245. 
12. I. Vermeulen, J. V. Caneghem, C. Block, J. Baeyens, C. Vandecasteele, Automotive shredder residue (ASR): reviewing its production from end-of-life vehicles (ELV) and its recycling, energy or chemicals' valorisation, J Hazard Mater, 190(1-3), 2011, 8-27.

13. V. A. Rossetti, L. D. Palma, F. Medici, Production of aggregate from non-metallic automotive shredder residues, J Hazard Mater, 137(2), 2006.

14. A. A. Zorpas, V. J. Inglezakis, Automotive industry challenges in meeting EU 2015 environmental standard, Technol in Soc, 34(1), 2012, 1-29.

15. G. Coates, C. Edwards, S. Rahimifard, T. Bhamra, P.Leaney, Cost-orientated approach to design and recovery of vehicles to meet the requirements for the end-of-life vehicle (ELV) Directive, Cent Sustain Manuf Reuse/Recycl Technol, 2006.

16. Recycling and Reuse: End-of-Life Vehicles and Producer Responsibility, http://www.epa.gov/oswer/international/factsheets/200811_elv_directive.htm.

17. European Parliament and the European Council. Directive 2000/53/EC of the European Parliament and the Council of 18th September 2000 on end-of-life vehicles, Off J Eur, 269(34), 2000, 34-42.

18. http://www.env.go.jp/en/press/2003/0808b.html.

19. B.J. Jody, E.J. Daniels, End-of-Life Vehicle Recycling: State of the Art of Resource Recovery from Shredder Residue, Argonne Natl Lab, 2010. 
20.http://www.env.go.jp/en/recycle/asian_net/Country_Information/Law_N_Regulatio n/Korea/Korea_RoHS_ELV_April_2007_EcoFrontier.pdf.

21. http://www.gov.cn/gongbao/content/2001/content_60919.htm.

22. http://www.shimadzu.com.cn/edx/statute/ELV/ELV-cn.pdf.

23. E. Guillaume, L. Marechal, Weight Reduction with Sandwich Material on Front End Carrier Application, SAE Technical Paper, 2008.

24. H. Antrekowitsch, G. Hanko, P. Paschen,. Recycling of Aluminium and Magnesium Parts from Used Cars: Legislative Frame and Consequences for Metallurgy and Material Design, SAE Technical Paper, 2001.

25. J. A. E. Månson, M.D. Wakeman, P. E. Bourban, P. W. Sunderland, Driving Forces for Cost-Effective Composites: New Demands on Materials and Processes, Intl Comm Compos Mater 2012 Proc, 2012.

26. G. Oliveux, J.Bailleul, E. Salle, Chemical recycling of glass fibre reinforced composites using subcritical water, Compos A: Appl Sci Manuf, 43(11), 2012, 1809-1818.

27. J. R. Correia, N. M. Almeida, J. R. Figueira, Recycling of FRP Composites: Reusing Fne GFRP Waste in Concrete Mixtures, J Clean Prod, 19(15), 2011.

28. E. Mangino, J. Carruthers, G. Pitarresi, The future use of structural composite materials in the automotive industry, Intl J Veh Des, 44(3-4), 2007, 211-232. 
29. G. Brady, H. Clauser, J. Vaccari, Materials Handbook, Fourteenth Ed., R. R. Donnelley \& Sons Company, 1997.

30. R. D. Adams, Adhesive bonding: science, technology and applications, Reinf Plast, 44, 2005.

31. M. Hornung, M. Hajj, Structural bonding for lightweight construction, Mater Sci Forum, 618-619, 2009, 49-56.

32. R. D. Adams, Structural Adhesive Joints in Engineering, Chapman and Hall, 1997.

33. S. Ebnesajjad, Adhesive Technology Handbook, Second Ed, William Andrew, 2008.

34. R. Sanchis, O. Fenollar, D. Garcia, L.Sanchez, R. Balart, Improved adhesion of LDPE films to polyolefin foams for automotive industry using low-pressure plasma, Intl J Adhes Adhes, 28(8), 2008, 445-451.

35. S. M. Anderson, Adhesives in Automotive Interiors - Versatile and Economical Bond Solutions, HYPERLINK "http://www.chemquest.com/PDF-

files/Adhesives_in_Automotive_Interiors.pdf" http://www.chemquest.com/PDF-

files/Adhesives_in_Automotive_Interiors.pdf

36. G. Michalos, S. Makris, N. Papakostas, D. Mourtzis, G. Chryssolouris, Automotive assembly technologies review: challenges and outlook for a flexible and adaptive approach, CIRP J Manuf Sci Technol, 2(2), 2010, 89-91. 
37. T. A. Barnes, I.R. Pashby, Joining techniques for aluminium spaceframes used in automobiles Part II adhesive bonding and mechanical fasterners, J Mater Process Technol, 99(1-3), 2000, 72-79.

38. G.S.Vasilash, The Lotus Elise -- a technological tour de force, Automot Manuf Prod, $109,1997,40-43$.

39. C. S. Adderley, Adhesive bonding, Mater Des, 9, 1988, 287-293.

40. J. Mortimer, Adhesive bonding of car body parts by industrial robot, Ind Robot Intl J, 31(5), 2004, 423-428.

41. D. A. Corlla, Automotive engineering: powertrain, chassis system and vehicle body, Elsevier, Oxford, 2009.

42.http://techcenter.lanxess.com/scp/americas/en/docguard/P_M_Hybrid_Solutions.pd f?docld=77014.

43.http://techcenter.lanxess.com/scp/americas/en/markscp/segments/article.jsp?docld $=105940$.

44.http://techcenter.lanxess.com/scp/americas/en/markets/article.jsp?docld=9042805.

45. L. Marechal, New metal plastic technology for front end modules, SAE Technical Paper, 2006. 
46. M. Grujicic, V. Sellappan, M. A. Omar, Norbert Seyr, A. Obieglo, M. Erdmann, J. Holzleitner, An overview of the polymer-to-metal direct-adhesion hybrid technologies for load-bearing automotive components, J Mater Process Technol, 197(1-3), 2008, 363-373.

47. P. Naughton, J. Röttger, B. Bowser, A new approach to hybrid front-end systems, SAE Technical Paper, 2002.

48. D. Recktenwald, Advanced adhesives foster hybrid structures, Mach Des, 77(21) 2005,124-126.

49. R. McCurdy. PhD thesis: disassembly methods for automotive structures, Oxford Brookes University, 2011.

50. Methods and apparatuses for detaching components adhesively bonded to one another, Patent Number US 20030127174,2003.

51. Reversible adhesive, Patent Number US 20050159521,2005.

52. J. F. Abrego, Carbon Dioxide Dissociation and Capture by Means of Ultrasound, J Appl Sci Res, 6(5), 2010, 469-472.

53. Specific adhesive compound suitable for easy removal, Patent Number US $6696124,2000$.

54. Betamate 4601 Medical Safety Data Sheet.

http://msdssearch.dow.com/PublishedLiteratureDOWCOM/dh_057a/0901b8038057aa 
34.pdf?filepath=/PublishTolnternet/InternetDOWCOM/msds/SDS_00075830_UNITEDST

ATES_ENGLISH\&fromPage=MSDS.

55. Solvent mixture for dissolving and removing epoxy resinous compounds, Patent

Number US 4278557,1980.

56. J. H. Michael, Re-working, removing, and "decapsulating" cured epoxy.

http://www.epotek.com/SSCDocs/whitepapers/Tech\%20Paper\%2046.pdf.

57. Reworkable epoxy die-attach adhesive, Patent Number US 5002818,1989.

58. Reworkable high temperature adhesives, Patent Number US 6380322,1999.

59. Cleavable diepoxide for removable epoxy compositions, Patent Number US $5560934,1996$.

60. Thermally reversible isocyanate-based polymers, Patent Number US 5470945,1995.

61. Bonding method employing thermo reversible crosslinking adhesives, Patent Number US 4744852,1988.

62. Methods of making and recycling rubber bodies bonded with a thermo-reversible, crosslinkable elastomer, Patent Number US 6746562,2004.

63. J. H.Aubert, Thermally removable epoxy adhesives incorporating thermally reversible diels-alder adducts, J Adhes, 79(6), 2003, 609-616. 
64. C.Toncelli, D. C. De Reus, F. Picchioni, A. A. Broekhuis, Properties of reversible dielsalder furan/maleimide polymer networks as function of crosslink density, Macromol Chem Phys, 213(2), 2012, 157-165.

65. http://masschallenge.org/profile/dc-polymers.

66. H. Shiote, C. Sato, M. Ohe, Effects of electrical treatment conditions on dismantlable properties of joints bonded with an electrically disbonding adhesive, J Adhes Soc Japan, 45(10), 2009, 376-381.

67. D. Haydon. ElectRelease - electrically disbonding epoxy adhesive, Assem Autom, 22(4), 2002, 326-329.

\section{S. Leijonmarck, A. Cornell, C. Danielsson, T. Akermark, B. D. Brandner.}

Electrolytically assisted debonding of adhesives: an experimental investigation, Intl J Adhes Adhes, 32, 2012, 39-45.

69. Adhesive system, Patent Number US 3938266,1973.

70. Adhesive system for form reversible glued joints, Patent Number US $6764569 B 1,2004$.

71. W. M. Obeidat, Recent patents review in microencapsulation of pharmaceuticals using the emulsion solvent removal methods, Recent Pat Drug Deliv Formul, 3(3), 2009, 178-192. 
72. Adhesive bonding method allowing nondestructive separation of bonded materials, Patent Number US 3993524,1976.

73. Adhesive composition, useful for bonding components and for detaching bonded components including e.g. metal, plastic, wood and natural or synthetic material, comprises an adhesive matrix with an expansion and a detaching material, Patent Number DE 19961940,2001.

74. Reworkable adhesives containing thermally labile groups, Patent Number US 0014924,2006 .

75. M. Minnicino, J. M. Sands, Reactive nanocomposites for controllable adhesive debonding, Army Res Lab, 2011.

76. Method of assembling two substrates by means of bonding and method of disassembling said bonded assembly by means of migration, Patent Number WO 2006/048585 A1, 2006.

77. Assembly of two substrates bonded by a rigid polymer, and methods for assembly and dismantling by means of migration of said bonded assembly, Patent Number US 20120258315 A1, 2012.

78. Heat debondable adhesive composition and adhesion structure, Patent Number WO $0040648,2000$.

79. F. B. Naini, D. S. Gill, Tooth fracture associated with debonding a metal orthodontic bracket: a case report, World J Orthod, 9(3), 2008,78-82. 
80. M. O. Oztoprak, D. Nalbantgil, A. S. Erdem, M. Tozlu, T. Arun, Debonding of ceramic brackets by a new, Am J Orthod Dentofacial Orthop, 138(2), 2010, 195-200.

81. T. Tsuruoka, Y. Namura, N. Shimizu, Development of an easy-debonding orthodontic adhesive using thermal heating, Dent Mater J, 26(1), 2007, 78-83.

82. Y. Nishiyama, N. Uto, C. Sato, H. Sakurai, Dismantlement behaviour and strength of dismantlable adhesive including thermally expansive particles, Intl J Adhes Adhes, 23(5), $2003,377-382$.

83. H. Ishikawa, K. Seto, S. Shimotuma, N. Kishi, C. Sato, Bond strength and disbonding behaviour of elastomer and emulsion-type dismantlable adhesives used for building materials, Intl J Adhes Adhes, 25(3), 2005, 193-199.

84. M. Jonsson, D. Nyström, O. Nordin, E. Malmström, Surface modification of thermally expandable microspheres by grafting poly(glycidyl methacrylate) using ARGET ATRP, Eur Polym J, 45(8), 2009, 2374-2382.

85. G. Manfre, The Dismantling Glass on ELV Needs Low Cost Technologies, http://www.glassfiles.com/library/3/article1012.htm.

86. G. Manfre, The Thermally Expanded Microspheres Debonding Technology and ELV Recycling Glazing, http://www.glassfiles.com/library/3/article708.htm.

87. S. Carter, Preparation and analysis of polypyrrole-coated TEM particles, Classified Report by De-Bonding Ltd, 2008. 
88. A. Schmid, L. R. Sutton, S. P. Armes, P. S. Bain, G. Manfre, Synthesis and evaluation of polypyrrole-coated thermally-expandable microspheres: an improved approach to reversible adhesion, J Soft Matter, 5, 2009, 407-412.

89.http://nano.evonik.com/sites/nanotechnology/en/technology/applications/magsilica /pages/default.aspx.

90. Curable bonded assemblies capable of being dissociated, Patent Number US $20040249037,2004$.

91. R. Bogue, Recent developments in adhesive technology: a review, Assem Automa, 31(3), 2011, 207-211.

92. T. Kuilla, S. Bhadra, D. Yao, N. H. Kim, S. Bose, J. H. Lee, Recent advances in graphene based polymer composites, Prog Polym Sci, 35(11), 2010, 1350-1375.

93. Switchable Adhesives, Patent Number US 2011/0224593 A1, 2009.

94. S. Sethi, L. Ge, L. Ci, P. M. Ajayan, A. Dhinojwala, Gecko-Inspired Carbon NanotubeBased Self-Cleaning Adhesives, Nano Lett, 8(3), 2008, 822-825.

95. N. Grassie, M. I. Guy, N. H. Tennent, Degradation of epoxy polymers: Part 1Products of thermal degradation of bisphenol-A diglycidyl ether, Polym Degrad Stab, 12(1), 1985, 65-91. 
96. C. Edwards, G. Coates, P. G. Leaney, S. Rahimifard, Implicaitons of the end-of-life vehicles directive on the vehicle recovery sector, Proceedings of the Institution of Mechanical Engineers, Part B: J Eng Manuf, 220 (7), 2006, 1211-1216.

97. http://epp.eurostat.ec.europa.eu/portal/page/portal/waste/.

98. http://low-powerdesign.com/sleibson/2011/05/01/future-cars-the-word-from-gmat-idc\%E2\%80\%99s-smart-technology-world-conference/. 